\section{OP0172-PARE WORKING TOGETHER FOR CHILDREN AND FAMILIES LIVING WITH RHEUMATIC AND MUSCULOSKELETAL DISEASES: THE EUROPEAN NETWORK FOR CHILDREN WITH ARTHRITIS (ENCA)}

Simon Stones ${ }^{1,2,3,4,5}$, Mirjam Kepic ${ }^{2,6}$, Saskya Angevare $^{2,7,8}$, Sammy Ainsworth ${ }^{2,3,9}$, Wendy Costello ${ }^{2,10}$, Anton Gruss ${ }^{2,11}$, Anita van de Louw ${ }^{2,12}$. ${ }^{1}$ Fibromyalgia Action UK, Paisley, United Kingdom; ${ }^{2}$ European Network for Children with Arthritis, Geneva, Switzerland; ${ }^{3}$ RAilSE, Clitheroe, United Kingdom; ${ }^{4}$ EULAR Young PARE, Kilchberg, Switzerland; ${ }^{5}$ University of Leeds, School of Healthcare, Leeds, United Kingdom; ${ }^{6}$ Društvo za pomoč otrokom z imunskimi boleznimi, Ljubljana, Slovenia; ${ }^{7} \mathrm{KAISZ}$, Utrecht, Netherlands; ${ }^{8}$ Autoinflammatory Alliance, San Francisco, United States of America; ${ }^{9}$ Alder Hey Children's NHS Foundation Trust, Liverpool, United Kingdom; ${ }^{10}$ Irish Children's Arthritis Network, Tipperary, Ireland; ${ }^{11}$ KOURIR, Paris, France; ${ }^{12}$ Jeugdreuma Vereniging Nederland, Apeldoorn, Netherlands

Background: The European Network for Children with Arthritis (ENCA) is a panEuropean network led for and by parents and young people with rheumatic and musculoskeletal diseases (RMDs). ENCA's activities are delivered voluntarily by parents and young people passionate about improving the care and treatment of children and young people (CYP) with RMDs. This is done through education, innovation, networking and empowerment. ENCA is associated with the Paediatric Rheumatology European Society (PReS).

Objectives: ENCA aims to facilitate the exchange and dissemination of information, knowledge and best practice with regards to paediatric RMDs across Europe, working in partnership with national patient organisations for CYP and families living with RMDs. ENCA also aims to provide international awareness, engagement and research opportunities.

Methods: ENCA is managed by a board of elected members, who are all volunteers with national patient organisations. ENCA hosts an annual conference in conjunction with PReS, inviting attendance from national patient organisations. Aside from a newly refreshed website, ENCA hosts a closed Facebook and WhatsApp group for national patient organisation representatives, enabling real-time communication and the instant sharing of knowledge and best practice. ENCA hosts an annual 'Fun with JIA challenge', aimed at empowering CYP with RMDs to share their story; and has been involved in establishing a new international awareness campaign for 2019, titled 'World young Rheumatic Disease (WORD) day'. In addition, ENCA cooperates with a number of international organisations with shared goals in rheumatology, representing the paediatric voice.

Results: Since its inception in 2002, ENCA has enhanced the communication and shared learning between national patient organisations, by embedding the voice of CYP and families into research and advocacy activities. The 'Fun with JIA challenge' delivered since 2017 has provided CYP with RMDs across Europe with the opportunity to share their stories through film. In addition, ENCAs' cooperation with PReS has recently facilitated the planning and launch of WORD day on March $18^{\text {th }}, 2019$. The need for a specific paediatric RMD awareness day was identified as a priority from national representatives, in light of the relatively limited attention that paediatric RMDs receive. WORD day helped to raise parental and professional awareness about paediatric RMDs.

Conclusion: As parents and young people living with RMDs, ENCA has enabled individuals and national patient organisations to develop their knowledge in relation to paediatric RMDs. ENCA provides several opportunities for networking and the sharing of best practices between national patient organisations and professionals, through informal and formal activities focused on paediatric RMDs. International networking helps individuals and communities to navigate through challenges with the support of others with a shared-goal.

\section{REFERENCE:}

[1] Egert $Y$, et al. PARE0005|Brief Overview of ENCA (European Network for Children with Arthritis). Ann Rheum Dis 2016; 75:1321.

Acknowledgement: ENCA would like to acknowledge PReS for their financial and professional support, and $\mathrm{MCl}$ for secretariat support.

Disclosure of Interests: Simon Stones Consultant for: SS has provided consultancy services to Envision Pharma Group, though this is not related to the contents of this abstract., Speakers bureau: SS has undertaken speaking engagements for Actelion, eyeforpharma, Four Health, Janssen and Roche, though these are not related to the contents of this abstract., Mirjam Kepic: None declared, Saskya Angevare: None declared, Sammy Ainsworth: None declared, Wendy Costello: None declared, Anton Gruss: None declared, Anita van de Louw: None declared

DOI: 10.1136/annrheumdis-2019-eular.1059
THURSDAY, 13 JUNE 2019

OSTEOARTHRITIS: RESEARCH IN MOTION

\section{OP0173 EROSIVE HAND OSTEOARTHRITIS ASSOCIATES WITH LOW OCCURRENCE OF KNEE OSTEOARTHRITIS}

Natividad Oreiro ${ }^{1}$, Ignacio Rego-Perez ${ }^{1}$, Sara Relaño-Fernandez ${ }^{1}$, Maria Teresa Silva ${ }^{1}$, Paula Ramos-Louro ${ }^{1}$, Alejandro Durán-Sotuela ${ }^{1}$, Sonia Pertega ${ }^{2}$, Francisco J. Blanco ${ }^{1} .1$ Instituto de Investigación Biomédica de A Coruña (INIBIC), Servicio de Reumatología, A Coruña, Spain; ${ }^{2}$ Instituto de Investigación Biomédica de A Coruña (INIBIC), Unidad de Epidemiología Clínica y Bioestadística, A Coruña, Spain

Background: Erosive hand osteoarthritis $(\mathrm{OA})$ is considered a more severe form of hand OA that includes pain and inflammation $(1,2)$. However, more data are needed regarding the different hand OA phenotypes, especially erosive and nonerosive, to conclude if they represent two different subsets of hand OA or even different degrees of affectation of the same disease $(1,3,4)$

Objectives: To compare the clinical pattern of patients with erosive hand $O A$ with those that do not show this phenotype

Methods: The study was conducted in the Prospective Cohort of Osteoarthritis A Coruna (PROCOAC). This cohort consists of 1107 subjects, of which 747 suffered from radiographic hand $\mathrm{OA}$. We split the cohort into patients with and without erosive hand $\mathrm{OA}$, and analyzed both clinical and demographic data within each group, together with the assessment of the AUStralian CANadian Osteoarthritis Hand (AUSCAN) index. The study consisted in a univariate analysis comparing different variables between both groups, followed by a stepwise logistic regression analysis taking into account the significant confounder variables analyzed in the Univariate approach

Results: The mean age of the cohort was $63.23 \pm 8.85$ years and consisted of 627 females and 120 males. Of the 747 OA patients, 179 had erosive hand OA and 568 did not. The univariate analysis revealed that patients with erosive hand $O A$ were younger $(60.25 \pm 8.10$ vs $64.16 \pm 8.88 ; p<0.001)$, smokers $(p=0.005)$, with lower body mass index $(p=0.005)$, increased inflammatory episodes $(p<0.001)$, with family history or suffering from psoriasis $(p=0.021)$ and less number of damaged joints $(p<0.001)$. In addition, metabolic syndrome (MetS) was not associated with erosive hand $O A$ and, despite the higher number of females suffering from hand $\mathrm{OA}$, no significant differences between erosive and non-erosive phenotypes in terms of gender were detected.

The regression model confirmed the strong association of age $(\mathrm{OR}=0.9734 ; 95 \%$ $\mathrm{Cl}=0.947-0.999 ; \mathrm{p}=0.044)$, inflammation ( $\mathrm{OR}=5.096 ; 95 \% \mathrm{Cl}=2.868-9.058$; $\mathrm{p}<0.001)$, number of damaged joints $(\mathrm{OR}=0.490 ; 95 \% \mathrm{Cl}=0.307-0.782 ; \mathrm{p}=0.003)$ and, interestingly, showed MetS as a risk factor too (OR=2.146; $95 \% \mathrm{Cl}=1.250$ 3.682; $p=0.006$ ). Regarding the number of damaged joints, a lower frequency of both knee and hip OA was detected in patients with erosive hand OA compared with non-erosive patients ( $24.4 \%$ vs $54.7 \%$ for knee OA prevalence and $11.6 \%$ vs $16.7 \%$ for hip OA prevalence); however, only knee OA occurred at a significant lower frequency $(\mathrm{OR}=0.267 ; 95 \% \mathrm{Cl}=0.182-0.393 ; p<0.001)$. In addition, the three subscales of the AUSCAN score showed significantly higher mean values in patients with the erosive phenotype: pain $(57.67 \pm 29.30$ vs $43.86 \pm 31.45$; $\mathrm{p}<0.001)$, function $(55.61 \pm 27.68$ vs $40.53 \pm 29.48 ; \mathrm{p}<0.001)$ and stiffness $(55.40$ \pm 32.26 vs $40.95 \pm 36.23 ; \mathrm{p}=0.001$ )

Conclusion: The erosive hand OA phenotype is associated with more inflammation in younger patients, and worst AUSCAN score. Contrarily to the non-erosive phenotype, the presence of erosions associates with a lower occurrence of other forms of OA, specially knee OA. In our cohort, erosive hand OA seems to be more localized in the hand and it also seems to be associated with psoriasis. This different profile could serve the clinicians to provide personalized prevention strategies, and the researchers to investigate the pathogenesis of this specific phenotype

\section{REFERENCES:}

[1] Haugen, et al. Osteoarthritis Cartilage 2016;24:647-654

[2] Marshall, et al. Ann Rheum Dis 2015;74:136-141

[3] Dolzani, et al. Clin Exp Rheumatol 2011;29:1006-1009

[4] Punzi, et al. Ann Rheum Dis 2005;64:955-957

Disclosure of Interests: Natividad Oreiro: None declared, Ignacio Rego-Perez: None declared, Sara Relaño-Fernandez: None declared, Maria Teresa Silva: None declared, Paula Ramos-Louro: None declared, Alejandro Durán-Sotuela: None declared, Sonia Pertega: None declared, Francisco J. Blanco Consultant for: AbbVie, Bioiberica, BMS, GSK, Grünenthal, Janssen, Lilly, Pfizer, Regeneron, Roche, Sanofi, TRB Chemedica, and UCB DOI: 10.1136/annrheumdis-2019-eular.4647 